\title{
Mobilising community collectivisation among female sex workers to promote STI service utilisation from the government healthcare system in Andhra Pradesh, India
}

\author{
Prabhakar Parimi, ${ }^{1}$ Ram Manohar Mishra, ${ }^{2}$ Saroj Tucker, ${ }^{3}$ Niranjan Saggurti ${ }^{2}$
}

${ }^{1}$ India HIV/AIDS Alliance, Hyderabad, Andhra Pradesh, India

${ }^{2} \mathrm{HIV}$ and AIDS Program, Population Council, New Delhi, India

${ }^{3}$ Clinical Services, India HIV/AIDS Alliance, Hyderabad, Andhra Pradesh, India

\section{Correspondence to} Dr Prabhakar Parimi, Regional Office, India HIV AIDS Alliance, Sarovar Centre, 5-9-22, Secretariat Road, Hyderabad-500063, Andhra Pradesh, India: pprabhakar@allianceindia.org

Accepted 10 February 2012 Published Online First 6 April 2012

\begin{abstract}
Background To assess the association between female sex workers' (FSWs) degree of community collectivisation and self-efficacy, utilisation of sexually transmitted infection (STI) services from government-run health centres in Andhra Pradesh, India.
\end{abstract}

Methods Cross-sectional analyses of 1986 FSWs recruited using a probability-based sampling from five districts of Andhra Pradesh during 2010-2011. Multiple logistic regression models were constructed to assess associations. The independent variables included-collective efficacy, collective agency and collective action-measured using a series of items that assessed the grouping of the community on issues that concern most sex workers. An additional independent variable included FSWs belonging to an area where there was a project partnership with government health centres to provide STI treatment services to FSWs. The outcome indicators included self-efficacy for service utilisation from government health facilities and the treatment for STls from government health facilities at least once in the past year experience of STI symptoms. Results Of the 1986 FSWs, nearly two-fifths (39.5\%) reported a high level of overall collectivisation (collective efficacy: 89\%, collective agency: 50.7\%; collective action: $12.7 \%)$. Sex workers with a high degree compared with low degree of overall collectivisation were significantly more likely to report high self-efficacy to use government health facilities $(75.0 \%$ vs $57.3 \%$, adjusted OR 2.5, 95\% $\mathrm{Cl} 2.0$ to 3.1 ) and to use government health centres for STI treatment in past 1 year (78.1\% vs $63.2 \%$, adjusted $\mathrm{OR} 2.1,95 \% \mathrm{Cl} 1.6$ to 2.8), irrespective of project partnership with government centres.

Conclusion The current research findings reinforce the need for stronger community mobilisation for better utilisation of government health facilities for STI and HIV prevention interventions.

\section{INTRODUCTION}

There is increasing evidence that the treatment of sexually transmitted infection (STI) among dispersed female sex workers (FSWs) and other marginalised populations, particularly those in rural areas, is more cost-effective and viable if these services are provided by a primary care physician. ${ }^{1-3}$ Such provider-based interventions call for project partnerships with government and/or private healthcare practitioners located in areas with high-risk population groups. ${ }^{4-6}$ With the evolution of National Rural Health Mission in India, ${ }^{7}$ there has been renewed interest in using the services of government and private healthcare facilities and providers, through sustainable partnerships, to reach at-risk populations within targeted HIV and other interventions in India. ${ }^{4} 89$ Although there have been significant efforts to promote the utilisation of services of primary care physicians in interventions targeted to FSWs in India, this has often been a challenge.

This paper focuses on a community mobilisation strategy adopted among FSWs to create a demand for the utilisation of STI services at government health facilities in five districts of Andhra Pradesh, India. Across the world, community mobilisation initiatives suggest several advantages associated with this strategy, including the empowerment of sex workers, reduced vulnerability to HIV and STI, increased condom use and reduced violence perpetrated by district or state administrative personnel. ${ }^{10-20}$ Although some studies highlight the difficulties in bringing sex workers together in some settings, given the high turnover due to their mobility, ${ }^{10}{ }^{16}$ most studies suggest that the collectivisation of FSWs is an effective method for increased community participation and achieving HIV/STI risk reduction outcomes. ${ }^{12}{ }^{21-25}$ In a study of 'community-led' health promotion in Sonagachi in Kolkata, India, the authors suggest that 'community mobilisation' refers to wider principles of involvement in or influence on the project and not merely a local grouping of marginalised sex workers. ${ }^{22} 26$ These studies have indicated the need to measure community mobilisation as collectivisation in response to the needs of sex workers within the community. To implement community mobilisation interventions for STI service utilisation in India, a number of issues need to be addressed, including strengthening government health facilities to provide STI treatment, reducing stigma and creating a demand for the use of government health services.

In this paper, we briefly describe the methods adopted to implement a community mobilisation intervention among FSWs and to build partnerships with government health facilities to deliver STI services in Andhra Pradesh. We then assess the effect of the degree of community collectivisation on FSWs' self-efficacy and their utilisation of STI care services from government health facilities by comparing FSWs from areas where the project partnered with government health facilities for STI 
treatment and FSWs from areas where STI services were provided by other methods. The intervention and evaluation data were collected as part of an ongoing 10-year (2004-2013) HIV prevention project among FSWs in Andhra Pradesh, which is being implemented by India AIDS Alliance (hereafter referred to as Alliance), a not-for-profit organisation working to prevent HIV and build healthy communities. Project activities included supporting community collectivisation among FSWs as part of an overall community mobilisation intervention across all intervention sites and building partnerships with government healthcare facilities in certain selected intervention sites.

\section{METHODS}

\section{Study setting}

The Alliance intervention covers a total of 14 districts with an estimated 36905 FSWs spread across both urban and rural areas of Andhra Pradesh. The intervention was initiated in 2004 and was scaled up across 68 sites by 2006; it was further extended to 139 sites, including 72 rural sites in 2007 . The estimated number of FSWs in the rural sites was 14180, with the majority dispersed across wide geographies.

Healthcare facilities available in the rural areas of Andhra Pradesh where FSWs reside and practice sex work include a primary health centre (PHC) and a community health centre $(\mathrm{CHC})$, presenting a typical scenario of primary healthcare settings across India. Each of these health centres includes a qualified doctor recruited by the government.

As FSWs in rural areas are scattered across wide geographies, providing STI service delivery through a static NGO clinic was not seen as a viable intervention. Rather, the project used the services of government-run PHCs, CHCs and Urban Health Center (UHCs) by establishing partnerships with these centres to provide cost-effective STI treatment to FSWs. To select intervention sites and to build such partnerships, the project mapped the fully functioning government and other health facilities located within a distance of $5 \mathrm{~km}$ from the target community areas. A total of 72 government health facilities were identified, which were fully functional in terms of infrastructure and where the doctor was willing to provide STI treatment services to the sex worker population.

Healthcare providers in these government facilities were trained on the syndromic management of STIs and provided an uninterrupted supply of colour-coded STI treatment kits and condoms. A project-supported auxiliary nurse-midwife was placed at each facility to conduct rapid syphilis screening and to oversee and support adherence to infection control practices and data recording.

The project promoted the utilisation of government-run facilities for STI services through its community collectivisation programme. The project team initiated sensitisation meetings with outreach staff and community members on the benefits of accessing STI treatment from government health facilities. Supervising NGOs supported community-based groups, formed as a result of community collectivisation efforts at the site level, to engage and mobilise FSWs to come together and to explain to the community the long-term benefits of accessing government facilities for STI treatment. It was emphasised that these centres would be a one-stop shop to meet FSWs' comprehensive health requirements, including their sexual and reproductive health needs. To create a demand for STI services at the hot spot level, awareness camps using games, street plays, puppet shows and magnet theatre shows were organised with a focus on building FSWs' risk perception. Overall, community collectivisation was conceived as a process to promote STI treatment service utilisation from government-run health centres.

\section{Data}

This paper uses data from the Behavioural Tracking Survey, a cross-sectional behavioural survey conducted among FSWs in five districts (Khammam, Warangal, Kurnool, Medak and Ananthapur) of Andhra Pradesh during 2010-2011 to monitor the key components of the HIV prevention programme: community mobilisation, safe sex behaviour and STI treatmentseeking behaviour. The districts were purposively selected for the survey to include areas where the HIV prevention programme was being implemented by Alliance, and no surveys specifically measuring community mobilisation had previously been conducted. A sample size of 400 FSWs was calculated for each district based on prevalence of consistent condom use and expected level of change with each unit change in the degree of community mobilisation. A total of 1986 FSWs from various sites were recruited through a two-stage sampling procedure. For FSWs based on non-public places (brothels, lodges similar to hotels for accommodation, roadside eating establishments and homes), the conventional cluster sampling approach was used by selecting hot spots. For FSWs based on public places (streets, market areas, highways and cinema halls), time-location cluster sampling was used where a hot spot was replicated multiple times to form a cluster for each time slot when FSWs congregate at the hot spot. ${ }^{27} 28$ In the second stage, within each selected hot spot, respondents were randomly selected. Details of sampling and the study design are discussed in another paper of this supplement. $^{29}$

\section{Ethical considerations}

The overall study design and questionnaires were reviewed and approved by the institutional review boards of Family Health International and the Karnataka Health Promotion Trust. Oral consent was obtained from all respondents prior to participation in the interview, and steps were taken to ensure their confidentiality. For ethical reasons, only those FSWs who were at least 18 years of age were interviewed. No names and addresses were recorded on the questionnaires. Participants were not provided any compensation for their time in the study but were referred to local project services run by Alliance in the study districts.

\section{Measures}

\section{Socio-demographic characteristics}

The socio-demographic characteristics considered in the paper were obtained from single-item questions in the questionnaire. Responses were coded into two or three categories for analytical purposes. The variables and their coding included: age, education (any formal schooling=1, no formal schooling=0), marital status (currently married $=1$, not currently married $=0$ ), typology of sex work (brothel-based=1, home-based=2, public placebased $=3$ ) and duration of sex work. Any formal schooling was defined as the ability to both read and write.

\section{Community collectivisation indicators}

We sought to measure three distinct dimensions of collectivisation: collective efficacy, collective agency and collective action. These indicators were measured using a series of questions in the questionnaire that assessed the grouping of the community on issues that concern most or all sex workers.

Collective efficacy refers to FSWs' confidence in the power of the community to work together for positive change in the 
interest of the community. We measured collective efficacy based on responses to the following four questions: How confident are you that FSWs in your community can work together to achieve the following goals: (1) keep each other safe from harm; (2) increase condom use with clients; (3) speak up for your rights and (4) improve your lives? Responses to these questions included: not at all (coded as 1), somewhat (coded as 2 ), very (coded as 3) and completely confident (coded as 4). Using these four questions and corresponding responses, an index was constructed, with the scale values ranging from 1 to 4 , which had a reliability (Cronbach's $\alpha$ ) of 0.796 . The index score was divided into two equal categories of collective efficacy: low (1-2.4999) and high (2.5-4).

Collective agency refers to FSWs' ability to claim their rights and make others accountable for their rights. This was measured based on responses to the question: In the past 6 months, have you negotiated with or stood up to the following stakeholders (police, madam/broker, local goon (gang member) and clients or any other sexual partner) in order to help a fellow sex worker? A separate question for each of the above stakeholders was asked, with the possible binary response categories 'Yes' (coded as 1) and 'No' (coded as 0). Using these questions and corresponding responses, an index was constructed, with the scale values ranging from 0 to 1 , which had a reliability (Cronbach's $\alpha$ ) of 0.756 . The index score was further divided into two equal categories of collective agency: low (0-0.4999) and high (0.5-1).

Collective action refers to the pursuit of a goal or set of goals by two or more individuals who work together. This was measured based on responses to the following six questions: Whether the sex workers group comes together to demand/help for the following: (1) voters' card, (2) bank account, (3) free education for children, (4) health insurance, (5) representation in government forums and (6) better government health services. Responses to these questions included 'Yes' (coded as 1) and 'No' (coded as 0). Using these six questions and corresponding responses, an index was constructed, with the scale values ranging from 0 to 1 , which had a reliability (Cronbach's $\alpha$ ) of 0.760 . The index score was further divided into two equal categories of collective action: low (0-0.4999) and high (0.5-1).

The summary measure of collectivisation was based on responses to all the questions used for the above three dimensions of collectivisation. For questions with two possible answers (viz., yes, no), the responses 'No' were re-coded as ' 1 ' and the responses 'Yes' were re-coded as '2'. Questions with four possible answers were taken as they were (as described above). The scores varied from 1 to 2.533, which had a reliability (Cronbach's $\alpha$ ) of 0.741 . The index score was further divided into two equal categories of the summary measure of collectivisation: low (1-1.7599) and high (1.7600-2.533).

\section{STI service delivery model}

Based on areas where the survey was conducted, the survey questionnaires recorded the kind of STI service delivery model implemented by the programme. Areas where project has made partnership with government health facilities (PHCs and CHCs) for STI treatment were referred as government partnership (coded as 1), and rest were considered to have other models of STI service delivery (coded as 0 ). The other type of STI service delivery models used in the programme was the project-run STI clinic, managed either by the programme implementing agencies or in partnership with private healthcare practitioners.

\section{Outcome indicators}

We considered two binary outcome indicators: (1) self-efficacy for service utilisation from government health facilities and (2) STI treatment-seeking from government referral health facilities. Self-efficacy for service utilisation from government health facilities was measured based on responses to the following two questions: (1) How confident are you that you can go to the government health clinic to get the reproductive health services you need if the health workers there treat you badly and (2) How confident are you that you can go to the government health clinic to get reproductive health services even if the health worker knows that you are a sex worker? Responses to these questions included: not at all (coded as 1), somewhat (coded as 2), very (coded as 3 ) and completely confident (coded as 4). Using responses to the two questions, an index was constructed with the scale values ranging from 1 to 4 , which had a reliability (Cronbach's $\alpha$ ) of 0.834 . The index score was further divided into two equal categories of self-efficacy for service utilisation from government health facilities: low (1-2.4999) and high (2.5-4).

For the outcome measure of STI treatment-seeking behaviour, two questions were asked. The first question assessed participants' experience of any of the following three STI symptoms at least once in the past 1 year: (1) genital sores/ulcers, (2) yellowish/greenish discharge from the vagina and (3) lower abdominal pain. All those who experienced STI symptoms were asked a question about the places they had visited for STI treatment. The multiple responses for this question included government health facilities, STI clinic administered by the NGO, private clinics or hospitals, private pharmacies, selfmedication and no treatment. A dummy variable measuring whether or not the respondent had sought STI treatment from government health facilities was derived. As respondents selected more than one answer for this question, those who reported seeking STI treatment from a government health facility at least once in the past year's experience of STI (irrespective of their visits to other places) were coded as 1 , and the remaining were coded as 0 .

\section{Statistical analyses}

Basic descriptive statistics (ie, proportions, means and SD) were presented to describe participants' socio-demographic characteristics, the strength of community collectivisation and the outcome indicators. Differences in proportions were tested using Z-test statistics, and differences in mean values were tested using $t$ test statistics. The analyses first examined the independent association of community collectivisation indicators and partnership with government health facilities with outcome indicators by estimating adjusted ORs and their 95\% CIs using multiple logistic regression models. Furthermore, to examine whether the effects of community collectivisation vary depending on the areas where the project had a partnership with government health facilities, data were grouped into four categories: (1) FSWs reporting a low level of collectivisation from areas with other STI service delivery models; (2) FSWs reporting a low level of collectivisation from areas with government partnerships; (3) FSWs with a high level of collectivisation from areas with other STI service delivery models and (4) FSWs with a high level of collectivisation from areas with government partnerships. In all multivariate analyses, we controlled for the socio-demographic characteristics considered in this paper. All analyses were conducted using STATA software (V.11.0). 


\section{RESULTS}

FSWs' socio-demographic characteristics, community collectivisation, self-efficacy and treatment-seeking behaviour for STI

Of the 1986 FSWs interviewed, 1116 (56.2\%) belonged to areas where STI services were delivered in partnership with government health facilities; the remaining 870 FSWs (43.8\%) were from areas where STI services were provided by other STI service delivery models (table 1). The mean age of the participants was 29 years, nearly half $(46.2 \%)$ had any formal schooling and close to three-fifths (57.1\%) were currently married. About two-thirds (63.8\%) solicited clients from public places such as streets, highways, parks and near cinema halls; the average duration of sex work was 4.4 years. About $90 \%$ reported a high degree of collective efficacy, and half $(50.7 \%)$ reported a high degree of collective agency. Only $13 \%$ of FSWs reported participation in collective action. The proportion of FSWs reporting high community collectivisation was found to be greater in areas where the project was a partnership with a government health facility for STI treatment than those without such a partnership (collective efficacy: $92.0 \%$ vs $85.1 \%$, $\mathrm{p}<0.001$; collective agency: $56.5 \%$ vs $43.2 \%, \mathrm{p}<0.001$ and overall collectivisation $41.5 \%$ vs $37.5 \%$, $\mathrm{p}=0.042$ ).

\section{Association between collectivisation, partnership with government health facilities and self-efficacy for service utilisation and STI treatment-seeking from government health facilities among FSWs}

Multiple logistic regression results presented in table 2 suggest that the odds of self-efficacy for service utilisation were significantly higher for the group with a high degree compared with those with a low degree of collective efficacy $(67.9 \%$ vs $35.2 \%$, adjusted OR $3.8,95 \%$ CI 2.8 to 5.1 ), those with a high degree compared with a low degree of collective agency $(75.2 \%$ vs $53.0 \%$, adjusted OR $2.8,95 \%$ CI 2.3 to 3.4 ) and those with a high degree compared with a low degree of collective action
( $78.5 \%$ vs $62.2 \%$, adjusted OR $2.5,95 \%$ CI 1.8 to 3.5 ). Similarly, the odds of seeking STI treatment from government health facilities was higher for the group with a high degree of overall collectivisation $(78.1 \%$ vs $63.2 \%$, adjusted OR $2.1,95 \%$ CI 1.6 to 2.8) compared with the group with a low degree of overall collectivisation. The self-efficacy for STI service utilisation from government health facilities was higher for those FSWs belonging to the areas where there was a project partnership with government health facilities than those belonging to areas without partnership (67.5\% vs $60.1 \%$, adjusted OR $1.4,95 \%$ CI 1.2 to 1.7$)$.

\section{Combined association of collectivisation and partnership with government health facilities with self-efficacy for service utilisation and STI treatment-seeking from government health facilities among FSWs}

The proportion of FSW with high self-efficacy for service utilisation varied significantly across the combinations of levels of collectivisation and service delivery models (table 3). Results suggest that the proportion of FSWs with high selfefficacy for service utilisation was low (54.0\%) among those who reported a low level of overall collectivisation from areas where STI services were not delivered through government health facilities. Compared with this group, the percentage of FSWs with high self-efficacy for service utilisation was higher among those who reported low levels of overall collectivisation from areas with government partnership $(59.9 \%$, adjusted OR 1.3, 95\% CI 1.0 to 1.6), who reported a high level of overall collectivisation from areas with other models of STI service delivery (70.3\%, adjusted OR 2.1, 95\% CI 1.6 to 2.9$)$ and who reported a high level of overall collectivisation from areas with government partnerships $(78.2 \%$, adjusted OR $3.4,95 \%$ CI 2.6 to 4.6). Similar results are noted for STI treatment at government health facilities, according to degree and type of collectivisation and project partnership with government health facilities.

Table 1 Socio-demographic characteristics, indicators of community collectivisation, experience of STIs and STI treatment-seeking behaviour by the project partnership with government health system among female sex workers in five districts of Andhra Pradesh, India

\begin{tabular}{|c|c|c|c|c|}
\hline \multirow[b]{2}{*}{ Socio-demographic characteristics } & \multirow{2}{*}{$\begin{array}{l}\text { Total sample } \\
(\mathrm{N}=1986) \\
\mathrm{n}(\%)\end{array}$} & \multicolumn{3}{|c|}{ Project partnership with government health facilities } \\
\hline & & $\begin{array}{l}\text { Yes }(n=1116) \\
\text { n }(\%)\end{array}$ & $\begin{array}{l}\text { No }(n=870) \\
\text { n }(\%)\end{array}$ & p Value* \\
\hline \multicolumn{5}{|l|}{ Demographic characteristics } \\
\hline Any formal schooling & $917(46.2)$ & $512(45.9)$ & $405(46.6)$ & 0.765 \\
\hline Currently married & $1134(57.1)$ & $665(59.6)$ & 469 (53.9) & 0.011 \\
\hline \multicolumn{5}{|l|}{ Typology of sex work } \\
\hline Brothels or lodges & $153(7.7)$ & $47(4.2)$ & $106(12.2)$ & $<0.001$ \\
\hline Mean duration of sex work (SD) & $4.4(2.4)$ & $4.3(2.4)$ & $4.5(2.5)$ & 0.086 \\
\hline \multicolumn{5}{|l|}{ Indicators of community collectivisation } \\
\hline Collective efficacy: high & $1768(89.0)$ & $1027(92.0)$ & $741(85.1)$ & $<0.001$ \\
\hline Collective agency: high & $1006(50.7)$ & $630(56.5)$ & $376(43.2)$ & $<0.001$ \\
\hline Taken treatment from government health facilities $\ddagger$ & $708(69.8)$ & $389(71.5)$ & $319(67.8)$ & 0.199 \\
\hline
\end{tabular}

${ }^{*} p$ Values are obtained by testing the significance of differences in percentages (Z-test) and mean values ( $t$ test) between the groups.

†Refers to the summary measure of collectivisation.

¥Among those who reported at least one of the following STI symptoms in the past 1 year: (1) genital sores/ulcers, (2) yellowish/greenish discharge from the vagina and (3) lower abdominal pain.

STI, sexually transmitted infections; SD, Standard deviation 
Table 2 Multiple logistic regression analyses assessing the associations between indicators of collectivisation, partnership with government health facilities and self-efficacy for service utilisation and STI treatment from government health facilities among female sex workers in Andhra Pradesh, India

\begin{tabular}{|c|c|c|c|c|c|c|}
\hline $\begin{array}{l}\text { Collectivisation and } \\
\text { service delivery model }\end{array}$ & \multicolumn{3}{|c|}{$\begin{array}{l}\text { Self-efficacy for service utilisation from government } \\
\text { health facilities }\end{array}$} & \multicolumn{3}{|c|}{ STI treatment from government health facilities } \\
\hline \multicolumn{7}{|l|}{ Collective efficacy } \\
\hline High & 1768 & $1201(67.9)$ & $3.8(2.8$ to 5.1$)$ & 953 & $682(71.6)$ & $4.0(2.3$ to 6.7$)$ \\
\hline \multicolumn{7}{|l|}{ Collective agency } \\
\hline Low & 980 & $519(53.0)$ & Referent & 457 & $295(64.5)$ & Referent \\
\hline Low & 1733 & $1078(62.2)$ & Referent & 857 & $582(67.9)$ & Referent \\
\hline High & 253 & $199(78.5)$ & 2.5 (1.8 to 3.5$)$ & 157 & $126(80.2)$ & $2.0(1.3$ to 3.0$)$ \\
\hline \multicolumn{7}{|c|}{ Summary measure of collectivisation } \\
\hline Low & 1201 & $688(57.3)$ & Referent & 569 & $360(63.2)$ & Referent \\
\hline High & 785 & $589(75.0)$ & $2.5(2.0$ to 3.1$)$ & 445 & $348(78.1)$ & $2.1(1.6$ to 2.8$)$ \\
\hline
\end{tabular}

*ORs were adjusted for following background characteristics: current age (entered as continuous variable), any formal schooling (no, yes) marital status (currently married, not currently married), typology of sex work (home-based, street-based, brothel-based) and duration of sex work (entered as continuous variable) using logistic regression.

STI, sexually transmitted infections.

\section{DISCUSSION}

Our findings show that FSWs who reported high collectivisation are significantly more likely than those who reported low levels of collectivisation to access STI treatment from government health facilities. These associations are not just a consequence of the presence of partnerships with government facilities for STI treatment, or of socio-demographic vulnerabilities, as the data suggest that FSWs from areas without partnerships with government health facilities also reported high attendance in government centres for STI treatment. Research is needed to explore why STI service utilisation from government health facilities is higher among FSWs who report or perceive higher levels of collectivisation than others. Previous evidence that a high degree of collectivisation and collective identity among FSWs lead to increased condom use and HIV risk reduction $^{12} 13 \quad 15 \quad 22-24 \quad 26$ may be interpreted to suggest that

Table 3 Multiple logistic regression analyses to assess the combined association of collectivisation indicators and partnership with government health facilities on self-efficacy for service utilisation and STI treatment from government health facilities among FSWs in Andhra Pradesh, India

\begin{tabular}{|c|c|c|c|c|c|c|}
\hline \multirow{2}{*}{$\begin{array}{l}\text { Levels of collectivisation by partnership with } \\
\text { government health facilities for STI treatment }\end{array}$} & \multicolumn{3}{|c|}{$\begin{array}{l}\text { Self-efficacy for service utilisation from government } \\
\text { health facilities }\end{array}$} & \multicolumn{3}{|c|}{ STI treatment from government health facilities } \\
\hline & $\mathbf{N}$ & $\mathbf{n}(\%)$ & Adjusted OR* $(95 \% \mathrm{Cl})$ & $\mathbf{N}$ & $\mathbf{n}(\%)$ & Adjusted $0 R^{*}(95 \% \mathrm{CI})$ \\
\hline \multicolumn{7}{|c|}{ Collective efficacy $\times$ Project partnership with government health facilities for STI treatment } \\
\hline Low $\times$ No & 130 & $39(29.8)$ & Referent & 38 & $14(36.2)$ & Referent \\
\hline Low $\times$ Yes & 89 & $39(43.3)$ & $1.9(1.1$ to 3.3$)$ & 24 & $12(49.7)$ & $2.1(0.7$ to 6.2$)$ \\
\hline High $\times$ No & 741 & $485(65.4)$ & $4.4(2.9$ to 6.6$)$ & 432 & $305(70.5)$ & $5.1(2.5$ to 10.6$)$ \\
\hline High $\times$ Yes & 1027 & $715(69.6)$ & $5.5(3.7$ to 8.4$)$ & 521 & $378(72.5)$ & $5.8(2.8$ to 11.9$)$ \\
\hline \multicolumn{7}{|c|}{ Collective agency $\times$ Project partnership with government health facilities for STI treatment } \\
\hline Low $\times$ No & 494 & $252(51.1)$ & Referent & 238 & $142(59.8)$ & Referent \\
\hline Low $\times$ Yes & 486 & $267(55.0)$ & $1.1(0.9$ to 1.5$)$ & 219 & $154(70.3)$ & 1.6 (1.1 to 2.4$)$ \\
\hline High $\times$ No & 376 & $270(71.9)$ & 2.5 (1.8 to 3.3$)$ & 232 & $178(76.6)$ & $2.3(1.5$ to 3.5$)$ \\
\hline High $\times$ Yes & 630 & $486(77.2)$ & $3.3(2.6$ to 4.4$)$ & 326 & $236(72.3)$ & 1.8 (1.3 to 2.6$)$ \\
\hline \multicolumn{7}{|c|}{ Collective action $\times$ Project partnership with government health facilities for STI treatment } \\
\hline Low $\times$ No & 773 & $450(58.2)$ & Referent & 399 & $264(66.2)$ & Referent \\
\hline Low $\times$ Yes & 960 & $628(65.4)$ & $1.4(1.1$ to 1.7$)$ & 458 & $317(69.3)$ & $1.2(0.9$ to 1.6$)$ \\
\hline High $\times$ No & 97 & $73(75.2)$ & $2.5(1.5$ to 4.1$)$ & 71 & $55(76.8)$ & 1.8 (1.0 to 3.2$)$ \\
\hline High $\times$ Yes & 156 & $126(80.5)$ & $3.5(2.3$ to 5.4$)$ & 87 & $72(83.1)$ & 2.5 (1.4 to 4.7$)$ \\
\hline \multicolumn{7}{|c|}{ Overall collectivisation $\times$ Project partnership with government health facilities for STI treatment } \\
\hline Low $\times$ No & 548 & $296(54.0)$ & Referent & 265 & $155(58.5)$ & Referent \\
\hline Low $\times$ Yes & 653 & $391(59.9)$ & $1.3(1.0$ to 1.6$)$ & 303 & $204(67.4)$ & $1.5(1.1$ to 2.1$)$ \\
\hline High $\times$ No & 322 & $226(70.3)$ & 2.1 (1.6 to 2.9$)$ & 204 & $163(79.9)$ & $2.9(1.9$ to 4.4$)$ \\
\hline High $\times$ Yes & 463 & $362(78.2)$ & $3.4(2.6$ to 4.6$)$ & 241 & $185(76.6)$ & $2.3(1.6$ to 3.4$)$ \\
\hline
\end{tabular}


FSWs have the ability and confidence to exercise their rights as citizens within the public health system, irrespective of health workers knowing their status. The current findings suggest that collectivisation in the presence of partnerships with government health facilities increases the rate of STI service utilisation from government centres more than if interventions focus only on collectivisation or only on improving the provision of STI services.

Notably, current findings are consistent with previous research documenting significant associations between collectivisation or indicators of community mobilisation and reduced sexual risk behaviours and HIV. ${ }^{13}{ }^{15}{ }^{22-26}$ Thus, the current research findings and previous evidence indicate that community collectivisation is a good strategy for changing health and treatment-seeking behaviour among FSWs populations in HIV prevention interventions. Such interventions could include strategies for creating an enabling environment that is safe for sex workers, ${ }^{17} 1830$ 31 ensuring consistent condom use with all types of partners ${ }^{22-24} 32$ and promoting STI treatmentseeking behaviour from government-supported STI treatment centres. ${ }^{4} 2531$ Hence, efforts to mobilise and build the capacity of sex workers and their communities are likely to improve their health and could be mainstreamed within targeted interventions supported by the National AIDS Control Programme. ${ }^{4}$

We found that although large proportions of FSWs reported high collective efficacy and collective agency, relatively few reported high collective action. However, the post hoc analyses suggest that about $38 \%$ of FSWs reported that the sex workers group had come together to demand or help FSWs to access at least one of the six entitlements. This result suggests that a greater proportion of sex workers reported group coming together for one or the other type of entitlements; however, higher degree at which they participate in such activities seems to be lower in this study population.

Although our findings offer important insights into the relationship between community collectivisation, the provision of STI services in government facilities and their effect on the selfefficacy of FSWs to use STI services from government health facilities in India, they must be interpreted in the light of certain study limitations. Most of the input indicators and outcomes were based on self- reports, which are vulnerable to social desirability and recall biases. Analyses are cross-sectional, and causality cannot be assumed; however, community collectivisation is an event that occurred over a period of time and much likely before the assessed outcomes; therefore, ordering of this exposure relative to self-efficacy for service utilisation can be assumed. Biases were also introduced into the study due to the nature of the sample. The samples drawn for the current study were from areas where the community mobilisation intervention was implemented. Although there are areas that were clearly identified by sites where the project has partnered with government health facilities, the mobile nature of sex workers may have disturbed the clear control subjects from that perspective. More importantly, government health facilities in the districts where the survey was undertaken also provide treatment for STI, irrespective of project partnership; however, the quality of services and the availability of skilled doctors and colour-coded kits for STI treatment are concerns in these facilities

An additional issue concerns the measurement of community collectivisation. Researchers both in India and in abroad have measured community mobilisation in multiple ways, such as collective identity, ${ }^{33-35}$ structural intervention ${ }^{36}$ or social policy and community participation. ${ }^{37} 38$ In view of this, the measures

\section{What is already known on this subject}

- Community mobilisation has an important influence on the lives of FSWs populations.

- Studies indicate that community mobilisation has an impact on HIV-related outcomes.

- Promotion of STI treatment from government-run health centres is a challenge.

- Health services, including STI treatment for FSW from government-run health centres, have several advantages as a long-term goal to achieve universal coverage in the control and management of STls.

\section{What this study adds}

- Self-efficacy for health service utilisation from government health centres (irrespective of special efforts to enhance the services within government centres) was strongly linked with the degree of community collectivisation.

- STI treatment from government health centres (irrespective of project partnership with government services) was strongly linked with the degree of community collectivisation.

- In the presence of both project partnerships with government health centres with enhanced provision of services and a high degree of collectivisation, service utilisation outcome indicators improve, even after controlling for socio-demographic characteristics.

used in the current paper may have some validation issues in settings other than sex work that measure community mobilisation. However, the results of our study are similar to many studies that focus on community mobilisation, whether within the HIV setting or the development sector, which points to the advantages associated with such efforts. Lessons learnt from our research and previous evidence suggest that community collectivisation works as a mechanism to popularise and build a demand for quality services at the ground level.

In conclusion, the current study documents that, irrespective of project partnerships with government health facilities for STI treatment, the degree of community collectivisation is predictive of self-efficacy and STI service utilisation from government health facilities. The results presented in this paper offer some support to the growing evidence of the effects of community collectivisation on HIV/STI risk reduction and highlight the need for programmes to provide ongoing support to communities to sustain the efforts that are built by programmes. Findings also reveal the need for targeted HIV interventions to focus on areas/sites where sex workers' perceive less collectivisation in order to increase their ability to access treatment from government health facilities. This work will be particularly important in rural areas, where FSWs are dispersed across a wide geography and where limited service delivery mechanisms exist.

Acknowledgements This paper was written as part of a mentorship programme under the Knowledge Network project of the Population Council, which is a grantee of the Bill \& Melinda Gates Foundation through Avahan, the India AIDS Initiative.

Contributors PP led the study design, conception and drafted the manuscript. RMM conducted the analyses and assisted with manuscript writing. ST participated in the 
design of the study and assisted with interpretation of study findings. NS provided overall guidance with analytical approach, manuscript writing and interpretation of study findings. All authors read and approved the final manuscript.

Funding Support for programme implementation was provided to the India AIDS Alliance via a grant from the Bill \& Melinda Gates Foundation through Avahan, the India AIDS Initiative. The views expressed herein are those of the authors and do not necessarily reflect the official policy or position of the Bill \& Melinda Gates Foundation and Avahan.

\section{Competing interests None}

Ethics approval Institutional review boards of the Family Health International and the Karnataka Health Promotion Trust.

Provenance and peer review Commissioned; externally peer reviewed.

\section{REFERENCES}

1. UNAIDS. Sexually transmitted diseases: policies and principles for prevention and care. 1997. http://www.unaids.org/en/media/unaids/contentassets/dataimport/ publications/irc-pub04/una97-6 en.pdf (accessed 10 Aug 2011).

2. Mignone J, Washington RG, $\bar{R}$ amesh BM, et al. Formal and informal sector health providers in southern India: role in the prevention and care of sexually transmitted infections, including HIV/AIDS. AIDS Care 2007;19:152-8.

3. Blanchard JF, Halli S, Ramesh BM, et al. Variability in the sexual structure in a rural Indian setting: implications for HIV prevention strategies. Sex Transm Infect 2007;83 (Suppl 1):i30-6.

4. National AIDS Control Organization (NACO). NACP-III - To Halt and Reverse the HIV Epidemic in India. New Delhi: India Ministry of Health \& Family Welfare, Government of India, 2006.

5. Gunn RA, Rolfs RT, Greenspan JR, et al. The changing paradigm of sexually transmitted disease control in the era of managed health care. JAMA 1998;279:680-4.

6. Mayaud P, McCormick D. Interventions against sexually transmitted infections (STI) to prevent HIV infection. Br Med Bull 2001;58:129-53.

7. Hota P. National rural health mission. Indian J Pediatr 2006;73:193-5.

8. International Labour Organization. Prevention of HIV/ AIDS in the World of Work: A Tripartite Response. Good Practices. New Delhi, India 2009. http://www.ilo.org/ wcmsp5/groups/public/_ed protect/_ protrav/_ilo aids/documents/publication/ wcms_119262.pdf (accessed 2 Sep 2011).

9. Kane $\overline{\mathbf{S}}$, Dewan PK, Gupta D, et al. Large-scale public-private partnership for improving TB-HIV services for high-risk groups in India. Int J Tuberc Lung Dis 2010;14:1066-8.

10. Campbell C, Mzaidume Z. Grassroots participation, peer education, and HIV prevention by sex workers in South Africa. Am J Public Health 2001:91:1978-86.

11. Cornish F, Campbell C. The social conditions for successful peer education: a comparison of two HIV prevention programs run by sex workers in India and South Africa. Am J Community Psychol 2009;44:123-35.

12. Cornish F, Ghosh R. The necessary contradictions of 'community-led' health promotion: a case study of HIV prevention in an Indian red light district. Soc Sci Med 2007;64:496-507.

13. Ghosh S, Maheswari T, DeZoysa C, et al. Community mobilisation of key populations critically reduces vulnerability and significantly increases positive outcomes of a STI prevention programme: results from a four-year impact evaluation study in Andhra Pradesh, India. AIDS 2008 - XVII International AIDS Conference 2008. http://www. iasociety.org/Default.aspx?pageld=11\&abstractld=200716502 (accessed 25 Aug 2011)

14. Shahmanesh M, Patel V, Mabey D, et al. Effectiveness of interventions for the prevention of HIV and other sexually transmitted infections in female sex workers in resource poor setting: a systematic review. Trop Med Int Health 2008:13:659-79.
15. Swendeman D, Basu I, Das S, et al. Empowering sex workers in India to reduce vulnerability to HIV and sexually transmitted diseases. Soc Sci Med 2009;69:1157-66.

16. Biradavolu MR, Burris S, George A, et al. Can sex workers regulate police? Learning from an HIV prevention project for sex workers in southern India. Soc Sci Med 2009;68:1541-7.

17. Campbell C, Nair Y, Maimane S. Building contexts that support effective community responses to HIV/AIDS: a South African case study. Am J Community Psychol 2007:39:347-63

18. Argento E, Reza-Paul S, Lorway R, et al. Confronting structural violence in sex work: lessons from a community-led HIV prevention project in Mysore, India. AIDS Care 2011:23:69-74.

19. Benzaken AS, Galban Garcia E, Sardinha JC, et al. [Community-based intervention to control STD/AIDS in the Amazon region, Brazil]. Rev Saude Publica 2007; 41/Supp 2):118-26.

20. Busza J, Baker S. Protection and participation: an interactive programme introducing the female condom to migrant sex workers in Cambodia. AIDS Care 2004;16:507-18

21. Cornish F. Challenging the stigma of sex work in India: material context and symbolic change. J Community App/ Soc Psychol 2006:16:462-71.

22. Jana $\mathbf{S}$, Singh S. Beyond medical model of STD intervention-lessons from Sonagachi. Indian J Public Health 1995:39:125-31.

23. Halli SS, Ramesh BM, O'Neil J, et al. The role of collectives in STI and HIV/AIDS prevention among female sex workers in Karnataka, India. AIDS Care 2006;18:739-49.

24. Blankenship KM, West BS, Kershaw TS, et al. Power, community mobilization, and condom use practices among female sex workers in Andhra Pradesh, India. AIDS 2008:22(Suppl 5):S109-16.

25. Nag M. Sex workers in Sonagachi- Pioneers of a revolution. Econ Political Weekly 2005; $40: 5151-6$

26. Jana S, Basu I, Rotheram-Borus MJ, et al. The Sonagachi Project: a sustainable community intervention program. AIDS Educ Prev 2004;16:405-14.

27. Magnani R, Sabin K, Saidel T, et al. Review of sampling hard-to-reach and hidden populations for HIV surveillance. AIDS 2005:19(Suppl 2):S67-72.

28. Saidel T, Adhikary R, Mainkar M, et al. Baseline integrated behavioural and biologica assessment among most at-risk populations in six high-prevalence states of India: design and implementation challenges. AIDS 2008;22(Suppl 5):S17-34

29. Swarup P, Somanath RP, Mishra RM, et al. Community advocacy groups as a means to address the social environment of female sex workers: a case study in Andhra Pradesh, India. J Epidemiol Community Health 2012;66:ii87-ii94.

30. Beattie T, Bhattacharjee P, Ramesh B, et al. Violence against female sex workers in Karnataka state, south India: impact on health, and reductions in violence following an intervention program. BMC Public Health 2010;10:476

31. Avahan. Avahan-The India AIDS Initiative: The Business of HIV Prevention at Scale New Delhi, India: Bill \& Melinda Gates Foundation, 2008.

32. Basu I, Jana S, Rotheram-Borus MJ, et al. HIV prevention among sex workers in India. J Acquir Immune Defic Syndr 2004;36:845-52.

33. Campbell C, MacPhail C. Peer education, gender and the development of critical consciousness: participatory HIV prevention by South African youth. Soc Sci Med 2002:55:331-45

34. Latkin CA, Knowlton AR. Micro-social structural approaches to HIV prevention: a social ecological perspective. AIDS Care 2005;17(Suppl 1):S102-13.

35. Ghose T, Swendeman D, George S, et al. Mobilizing collective identity to reduce HIV risk among sex workers in Sonagachi, India: the boundaries, consciousness, negotiation framework. Soc Sci Med 2008;67:311-20.

36. Blankenship K, Friedman S, Dworkin S, et al. Structural interventions: concepts, challenges and opportunities for research. J Urban Health 2006;83:59-72.

37. Kothari U. Power, knowledge and social control in participatory development. In: Cooke B, Kothari U, eds. Participation: The New Tyranny?. London: Zed Books, 2001.

38. Chambers R. Whose Reality Counts? Putting the First Last. UK: Intermediate Technology Publications, 1997. 